\title{
Low FEV1 is Associated with Fetal Death in Pregnant Women with Sickle Cell Disease: a prospective cohort study
}

\author{
Charles Hayfron-Benjamin ${ }^{1}$, Eugenia Asare ${ }^{2}$, Theodore Boafor ${ }^{3}$, Edeghonghon Olayemi ${ }^{2}$, \\ Yvonne Dei-Adomakoh ${ }^{2}$, Latif Musah ${ }^{1}$, Enoch Mensah ${ }^{1}$, Titus Beyuo ${ }^{3}$, Adetola Kassim \\ ${ }^{4}$, Mark Rodeghier ${ }^{5}$, Michael DeBaun ${ }^{4}$, and Samuel Oppong ${ }^{3}$ \\ ${ }^{1}$ University of Ghana Medical School \\ ${ }^{2}$ Ghana Institute of Clinical Genetics \\ ${ }^{3}$ Korle $\mathrm{Bu}$ Teaching Hospital \\ ${ }^{4}$ Vanderbilt University Medical Center \\ ${ }^{5}$ Rodeghier Consultants
}

May 5, 2020

\begin{abstract}
Objective: We tested the hypothesis that impaired maternal gestational pulmonary function, assessed by a moderate-to-severe reduction in FEV1\% predicted, is associated with adverse perinatal outcomes in women with SCD. Design: Prospective cohort study. Setting: Tertiary referral centre Population: A total of 104 pregnancies in Ghanaian women with SCD aged 18-41 years. Methods: Participants were categorized into two groups (FEV1\% predicted [?] 65: $\mathrm{n}=94 ;$ FEV1\% predicted $<65: \mathrm{n}=10$ ) based on spirometry performed before 28 weeks of pregnancy. The rates of adverse perinatal outcomes were compared between the two groups. Multivariable penalized logistic regression was used to estimate adjusted odds ratios. Main outcome measure: Fetal death, defined as fetus weighing $>500 \mathrm{~g}$ with no signs of life at birth. Results: Fetal death occurred more frequently in pregnant women with FEV1\% predicated $<65$ (30.0\% versus $4.3 \%, \mathrm{p}=0.02)$. FEV1\% predicted $<65$ was associated with a nearly 8-fold increased risk of fetal death (OR 7.81, 95\% CI [1.59-38.38], p=0.01). Phenotype HbSS (3.41[0.68-17.19], p=0.13) and low maternal BMI (1.00 [0.84-1.20], p=0.96) were not associated with increased risk of fetal death. Conclusions: In pregnant women with SCD, low FEV1\% predicted is associated with an increased risk of fetal death. Understanding the mechanism for low FEV1\% predicted in pregnant women with SCD and improving gestational FEV1\% predicted may result in a targeted intervention for decreasing fetal deaths. Keywords: Sickle cell disease, pulmonary function, FEV1, pregnancy outcomes, fetal death.
\end{abstract}

\section{Introduction}

In pregnancy, a combination of hormonal changes and mechanical effects of the enlarging uterus may result in pulmonary changes including rhinitis of pregnancy, sleep-disordered breathing, and small airway closure 1. Sickle cell disease (SCD), the commonest genetic disease in the world, affects multiple organ systems including the respiratory system ${ }^{2}$. Specifically, SCD is associated with reduced lung growth, airway hyperresponsiveness, pulmonary hypertension, and acute chest syndrome (ACS $)^{2-5}$. The combined effects of pulmonary changes in pregnancy and SCD may result in substantial reductions in maternal pulmonary reserves ${ }^{1,6}$, with resultant uteroplacental dysfunction and reduced fetal oxygenation ${ }^{1,6,7}$.

In a systematic review and meta-analysis, we demonstrated that pregnant women living with SCD have increased risk of maternal and perinatal morbidity and mortality ${ }^{8}$. In contrast to poor maternal outcomes ${ }^{8-10}$, the biological basis of the poor perinatal outcomes is not clear, although factors such maternal body mass index (BMI) and SCD phenotype have been implicated ${ }^{11,12}$. One potential modifiable risk factor is 
the role of abnormal pulmonary function in pregnant women with SCD on the outcome of the fetus. In a prospective cohort study of pregnant women with SCD, we tested the hypothesis that impaired pulmonary function during pregnancy, assessed by a moderate to severe reduction in baseline forced expiratory volume in one second $\left(\mathrm{FEV}_{1}\right)$, is associated with increased risk of adverse perinatal outcomes in pregnant women with SCD.

\section{Methods}

\section{Study Design and Settings}

The prospective cohort study included pregnant women with SCD at the Korle-Bu Teaching Hospital (KBTH), Ghana, from May 2015 to December 2016. The primary outcomes of the study were maternal and perinatal mortality rates. KBTH is a tertiary referral hospital in Ghana's capital, Accra, and the largest specialist hospital in Ghana. The maternity unit attends to about 11000 pregnant women annually including 200 pregnant women with SCD.

\section{Recruitment}

A total of 149 pregnant women with established diagnosis of SCD were recruited. This excluded women who were referred with acute pregnancy-related complications, in active labor, or after delivery, and those who were unable to comply with the follow-up requirements for prenatal visits. The diagnosis of SCD was determined by cellulose acetate hemoglobin electrophoresis at alkaline $\mathrm{pH}$. For the current analyses, data from 104 pregnant women (HbSS: 40; HbSC: 64) who had spirometry testing within 2 weeks of enrolment, and followed up for at least 12 weeks (at least 6 weeks while pregnant and 6 weeks post-delivery) were included (Figure 1). All study participants received multi-disciplinary care, described in detail in a previous publication $^{13}$.

\section{Data Collection}

A structured questionnaire was used by a trained research nurse to collect participant data. Data collected included demographics, gestational ages at enrolment and delivery, duration of follow-up during the pregnancy and postpartum periods, antenatal complications, postpartum complications, mode of delivery, and neonatal information. Laboratory evaluations included complete blood count, blood screening for malaria and spirometry. Study data were managed using REDCap (Research Electronic Data Capture) electronic data capture tools hosted at the Data Coordinating Center, Vanderbilt University Medical Center. REDCap is a secure, web-based application designed to support data capture for research studies, providing (a) an intuitive interface for validated data entry; (b) audit trails for tracking data manipulation and export procedures; (c) automated export procedures for seamless data downloads to common statistical packages; and (d) procedures for importing data from external sources.

\section{Assessment of Maternal Outcomes.}

Acute painful episode was defined as acute pain episodes leading to hospitalization that required oral or intravenous opioid pain management, distinguished from labour pains by absence of uterine contraction, labour progression, and delivery. Based on the adjudication of the multi-disciplinary team (obstetricians, hematologists, anesthetists, pediatricians, and nurses), ACS was defined as the presence of at least 2 of the following criteria: fever $>38^{\circ}$ Celsius, increased respiratory rate $>20$ breaths per minute, presence of chest pain or pulmonary auscultatory findings, increased oxygen requirement (evidenced by a decrease in $\mathrm{SpO} 2>3 \%$ below the baseline) or new radiodensity on chest roentgenogram or pneumonia. Preeclampsia was defined as 1) systolic blood pressure (SBP) [?] $140 \mathrm{mmHg}$ or diastolic blood pressure (DBP) [?] 90 $\mathrm{mmHg}$ on two separate readings taken at least four hours apart after 20 week gestation in a study participant with previously normal blood pressure; and 2) Proteinuria as [?] $300 \mathrm{mg}$ of protein in a 24-hour urine sample or a spot urinary protein to creatinine ratio [?] 0.3 or a urine dipstick reading of $1+$ or greater ${ }^{14}$. Malaria infection was defined using the World Health Organization definition of examining stained thick smears under the light microscope ${ }^{15}$. 


\section{Assessment of Perinatal Outcomes.}

Gestational age was estimated based on first trimester ultrasound scan. Serial obstetric ultrasounds were performed bi-weekly in the third trimester to monitor fetal growth. Umbilical artery Doppler studies were performed in those with suspected intrauterine growth restriction (IUGR). Premature birth was defined as births that occurred before 37 weeks of gestation. Low birth weight (LBW) and very low birth weight (VLBW) were defined as birth weights below 2,500 and 1500 grams respectively. Fetal death was defined as a fetus weighing greater than $500 \mathrm{~g}$ with no signs of life at birth and meeting all the following criteria; no fetal heartbeat; no respiratory effort; absence of pulsation in the umbilical cord; and no definitive movement of voluntary muscles.

\section{Spirometry Evaluation.}

A trained physician and a trained research technician performed spirometry for each participant at baseline visit ( $<28$ weeks of pregnancy) using the Morgan FVL spirometer according to the American Thoracic Society/European Respiratory Society (ATS/ERS) guidelines ${ }^{16}$. The spirometry procedure was first demonstrated to each participant, after which the participant was made to perform the spirometry. Each participant was made to inhale rapidly and completely from functional residual capacity, after which the breathing tube was inserted into the participant's mouth, with the lips sealed around the mouthpiece and the tongue not occluding the mouthpiece. The forced vital capacity (FVC) maneuver was then started with minimal hesitation (within 1-2 seconds after inspiring to the total lung capacity). The participant was prompted to "blast" the air from their lungs, and was then encouraged to fully exhale. Throughout the FVC maneuver, enthusiastic coaching of each participant was carry out using appropriate body language and phrases, such as "keep blowing" or "keep going". Measured and calculated spirometric indices from the FVC maneuver included $\mathrm{FEV}_{1}, \mathrm{FVC}$, and the ratio of $\mathrm{FEV}_{1}$ to $\mathrm{FVC}\left(\mathrm{FEV}_{1} / \mathrm{FVC}\right)$. The predicted values of the $\mathrm{FEV}_{1}$, $\mathrm{FVC}$, and the $\mathrm{FEV}_{1} / \mathrm{FVC}$ ratio were determined for each participant based on their age, gender, height, and ethnic group using the Global Lung Initiative 2012 equations ${ }^{17}$. Poor lung function was defined as $\mathrm{FEV}_{1} \%$ predicted $<65^{18,19}$. The choice of 0.65 as the threshold for $\mathrm{FEV}_{1} \%$ predicted is based on its predictive value for mortality in the general population ${ }^{19}$.

\section{Statistical Analysis}

Data with normal distribution were presented as mean (standard deviation); whereas, those not normally distributed were presented as median (interquartile range). Categorical data were presented as frequencies (percentages). Differences in demographic characteristics and pregnancy outcomes between the $\mathrm{FEV}_{1} \%$ predicted [?] 65 and $\mathrm{FEV}_{1} \%$ predicted $<65$ groups were assessed by chi-square test or Fisher's exact test for categorical variables, and t-test for continuous covariates or the Mann-Whitney U-test for covariates not normally distributed. Given the small number of fetal deaths, a multivariable penalized logistic regression was used to estimate adjusted odds ratios with $95 \%$ confidence intervals. For the same reason, only a small number of covariates were used in the model. A $p$ value of less than 0.05 was considered statistically significant. IBM SPSS version 25 for Windows was used for statistical analysis.

\section{Results}

The proportion of HbSS phenotype was similar in the group with $\mathrm{FEV}_{1} \%$ predicted [?] 65 and the group with $\mathrm{FEV}_{1} \%$ predicted $<65$, as was the proportion of HbSC phenotype (Table 1). Additionally, maternal parity was similar in the two $\mathrm{FEV}_{1} \%$ predicted groups. Moreover, the two $\mathrm{FEV}_{1} \%$ predicted groups were similar with respect to the mean maternal ages, gestational ages, maternal BMI, and hemoglobin concentrations. The mean FVC \% predicted and $\mathrm{FEV}_{1} / \mathrm{FVC} \%$ predicted were higher in the $\mathrm{FEV}_{1} \%$ predicted [?] 65 group compared with the $\mathrm{FEV}_{1} \%$ predicted $<65$ group.

\section{Low FEV $_{1} \%$ Predicted is a Significant Predictor of Fetal Death}

The rate of fetal death was higher in participants with $\mathrm{FEV}_{1} \%$ predicted $<65$ compared to those with $\mathrm{FEV}_{1} \%$ predicted [?] 65 (30.0\% versus $\left.4.3 \%, p=0.01\right)$ with an overall prevalence of $6.8 \%$ (7 of 103$)$ (Table 2 ). In a multivariable penalized regression model, $\mathrm{FEV}_{1} \%$ predicted $<65$ was associated with a nearly 8 -fold 
increased risk of fetal death (OR 7.81, 95\% CI [1.59-38.38], $p=.011$ ) (Table 3). Phenotype (HbSS) (3.41 [0.68-17.19], $\mathrm{p}=0.13)$ and low maternal BMI $(1.00[0.84-1.20], \mathrm{p}=0.95)$ were not associated with fetal death.

The preterm delivery rate of $30.1 \%$ in pregnant women with SCD was high, as compared with the rates expected in the general population (10\%). A non- statistically significant difference in the preterm delivery rate occurred between the $\mathrm{FEV}_{1} \%$ predicted $<65$ group compared to the $\mathrm{FEV}_{1} \%$ predicted [?] 65 group ( $50.0 \%$ versus $28.0 \%$, respectively; $p=.163)$. The difference in the rates of IUGR, LBW, and VLBW between the $\mathrm{FEV}_{1} \%$ predicted [?] 65 group and the $\mathrm{FEV}_{1} \%$ predicted $<65$ group were also not statistically significant. (Table 2)

\section{Similar Rates of Maternal Outcomes in FEV $_{1} \%$ Predicted [?] 65 and FEV $1 \%$ Predicted $<65$ Groups}

$\mathrm{FEV}_{1} \%$ predicted $<65$ when compared to $\mathrm{FEV}_{1} \%$ predicted $>65 \%$ was not associated with severe acute pain episodes that required hospitalization or ACS episodes. Similarly, $\mathrm{FEV}_{1} \%$ predicted $<65$ was not associate with preeclampsia, hospitalization for malaria, medically assisted delivery including cesarean section, and maternal deaths, Table 2.

\section{Discussion}

\section{Main findings}

For the first time, we have demonstrated that reduced maternal gestational pulmonary function, assessed by moderate-to-severe reductions in baseline $\mathrm{FEV}_{1} \%$ predicted is a significant predictor of fetal death. There was no significant association between low maternal $\mathrm{FEV}_{1} \%$ predicted and adverse maternal outcomes including ACS, acute painful episodes and maternal deaths.

\section{Strengths and limitations}

This study has a number of key strengths. Our study contributes unique data, as there are no prior studies evaluating the impact of maternal pulmonary function on perinatal outcomes in SCD. The prospective study design has inherent strengths including a decreased likelihood of recall bias. The study participants received care from a multi-disciplinary team including local obstetricians and gynecologists, hematologists, midwives, laboratory scientists, a pediatrician, and a dual-certified anesthesiologist and pulmonologist, as well as SCD experts from Vanderbilt University and an obstetrician and gynecologist from Duke University Medical Center. This ensured higher quality decision-making and standardized patient care ${ }^{20}$.

A significant limitation to this study is the lack of pre-gestational pulmonary function test. In persons with chronic lung disease, pre-gestational $\mathrm{FEV}_{1} \%$ predicted is known to correlate well with pregnancy outcomes 21,22 . However, changes in maternal pulmonary function during pregnancy may not be influenced by pregestational pulmonary function status ${ }^{21}$. Our study is also limited by phenotype distribution (HbSS versus $\mathrm{HbSC}$ ). However, the differences in proportion of $\mathrm{HbSS}$ and $\mathrm{HbSC}$ in the $\mathrm{FEV}_{1} \%$ predicted groups were not statistically significant.

\section{Interpretation}

Previous studies have demonstrated significant reductions in pulmonary functional reserves in SCD ${ }^{2,4}$. Also, existing data show strong associations between reduction in $\mathrm{FEV}_{1} \%$ predicted and SCD-related morbidity and mortality ${ }^{23-25}$. What remains unclear is whether reduction in pulmonary function in pregnant women with SCD is associated with adverse pregnancy outcomes. The results of our study suggest that in pregnant women with $\mathrm{SCD}$, low $\mathrm{FEV}_{1} \%$ predicted is associated with an increased risk of fetal death

In the general population, low $\mathrm{FEV}_{1} \%$ predicted or decline in $\mathrm{FEV}_{1}$ has been shown to be associated with mortality ${ }^{21,24-28}$. Also in the general population, $\mathrm{FEV}_{1} \%$ predicted is a known robust predictor of sudden cardiac death, with the relationship independent of cardiac function ${ }^{26,28}$. In addition our team has previously demonstrated that low $\mathrm{FEV}_{1} \%$ predicted is a predictor of earlier death in young adults with SCD and future ACS episodes ${ }^{27}$. 
Prior studies have indicated that low $\mathrm{FEV}_{1} \%$ predicted during pregnancy is associated with adverse perinatal outcome in pregnant women with cystic fibrosis ${ }^{21,22,29,30}$; however, the biological basis for this association has not been elucidated. Reynaud et al . have reported that pregnancy in women with cystic fibrosis and poor pulmonary function has a negative impact on fetal growth ${ }^{21}$. Other retrospective analyses of pregnancies in women with cystic fibrosis have further highlighted low maternal baseline $\mathrm{FEV}_{1} \%$ predicted as a predictor of premature delivery, LBW and fetal death ${ }^{22,29,30}$. These findings in pregnant women with cystic fibrosis lend credence to the biological plausibility that observed association between lower $\mathrm{FEV}_{1} \%$ predicted and fetal death in SCD.

We found no significant association between low maternal $\mathrm{FEV}_{1} \%$ predicted and adverse maternal outcomes including ACS, acute painful episodes and maternal deaths. Although we found no statistical difference between the rates of acute painful episodes, ACS, and deaths in women with baseline $\mathrm{FEV}_{1} \%$ predicted [?] 65 and those with $\mathrm{FEV}_{1} \%$ predicted $<65$, the mean events per patient year for acute pain episodes and ACS, and maternal mortality were higher $\left(33 \%, 150 \%\right.$, and $370 \%$ respectively) in the group with $\mathrm{FEV}_{1} \%$ predicted $<65$, compared to the group with $\mathrm{FEV}_{1} \%$ predicted [?] 65. The lack of statistically significant difference in our study may be due to limited power or the natural short follow-up period during pregnancy. These limitations can be overcome with larger multi-center prospective studies.

\section{Conclusion}

In pregnant women with SCD, poor baseline gestational pulmonary function is a significant predictor of fetal death. Stratification based on $\mathrm{FEV}_{1} \%$ predicted may add valuable information on perinatal risk assessment in pregnant women with SCD. Understanding the mechanism for low $\mathrm{FEV}_{1} \%$ predicted in pregnant women with $\mathrm{SCD}$ and improving gestational $\mathrm{FEV}_{1} \%$ predicted may result in a targeted intervention for decreasing fetal deaths.

\section{Acknowledgments}

The authors acknowledge the late Prof. Samuel Amenyi Obed and the leadership of the Department of Obstetrics and Gynecology, KBTH for administrative support, funds from University of Ghana, Office of Research, Innovation and Development (ORID); Doris Duke Charitable Foundation; Burroughs Wellcome Foundation, Phillips Family Donation; Aaron Ardoin Foundation for Sickle Cell Anemia; and J.C. Peterson, M.D. endowed chair funds from Vanderbilt University School of Medicine. We also acknowledge the donation of pulse oximetry machines by the team from Vanderbilt University Medical Center.

\section{Disclosure of interests}

None declared. Completed disclosure of interests forms are available to view online as supporting information.

\section{Funding}

Office of Research Innovation and Development (ORID), University of Ghana, Doris Duke Charitable Foundation, Burroughs Wellcome Foundation, Phillips Family Donation, Aaron Ardoin Foundation for Sickle Cell Anemia; Vanderbilt University School of Medicine (J.C. Peterson, M.D.); Office of Research and Innovation and Development (ORID) Research Fund/8/LMG-008, University of Ghana (awarded to EO and SAO) and Vanderbilt University Medical Center Gift Funds; the National Center for Research Resources, Grant/Award Number: Grant UL1 RR024975-01; the National Center for Advancing Translational Sciences, Grant/Award Number: Grant 2 UL1 TR000445-06

\section{Contribution to authorship}

SAO, CFHB, EO, AAK, and MRD conceived the idea; CFHB, SAO, EVA, EO, TKB, LM and YDA performed the experiment; MR, CFHB, EVA, SAO and MRD analyzed and interpreted the data; CFHB, EVA, TKB, EO, YDA, LM, EM, TB, AAK, RD, MRD, and SAO authors participated in writing the article, reviewed and approved the final version before submission.

\section{Details of ethics approval}


The study received ethical approval from the Ethical and Protocol Review Committee of the College of Health Sciences, University of Ghana (MS-Et/M.12-P4), and Vanderbilt University Medical Center (VUMC) Institutional Review Board, Nashville, TN, USA (VUMC IRB \#141050). The ethical approval was obtained in 2014 .

\section{REFERENCES}

1. Hegewald MJ, Crapo RO. Respiratory physiology in pregnancy. Clin Chest Med. 2011 Mar;32(1):1-13.

2. Ardiles T, Dark D. Pulmonary complications of sickle cell disease in adults. Mo Med. 2007;104(3):250-4.

3. Field JJ, DeBaun MR, Yan Y, Strunk RC. Growth of lung function in children with sickle cell anemia. Pediatr Pulmonol. 2008 Nov;43(11):1061-6.

4. Minter KR, Gladwin MT. Pulmonary Complications of Sickle Cell Anemia. Am J Respir Crit Care Med. 2001 Dec 1;164(11):2016-9.

5. Miller AC, Gladwin MT. Pulmonary Complications of Sickle Cell Disease. Am J Respir Crit Care Med. 2012 Jun 1;185(11):1154-65.

6. Stone SE, Morris TA. Pulmonary embolism during and after pregnancy. Crit Care Med. 2005 Oct;33(10 Suppl):S294-300.

7. Tong W, Giussani DA. Preeclampsia Link to Gestational Hypoxia. J Dev Orig Health Dis. 2019 Jun;10(3):322-33.

8. Boafor T, Olayemi E, Galadanci N, Hayfron-Benjamin C, Dei-Adomakoh Y, Segbefia C, et al. Pregnancy outcomes in women with sickle-cell disease in low and high income countries: a systematic review and meta-analysis. BJOG Int J Obstet Gynaecol. 2016 Apr 1;123(5):691-8.

9. Pereira A, Krieger BP. Pulmonary complications of pregnancy. Clin Chest Med. 2004 Jun;25(2):299-310.

10. Zeldis SM. Dyspnea during pregnancy. Distinguishing cardiac from pulmonary causes. Clin Chest Med. 1992 Dec;13(4):567-85.

11. Elenga N, Adeline A, Balcaen J, Vaz T, Calvez M, Terraz A, et al. Pregnancy in Sickle Cell Disease Is a Very High-Risk Situation: An Observational Study [Internet]. Obstetrics and Gynecology International. 2016 [cited 2019 Oct 14]. Available from: https://www.hindawi.com/journals/ogi/2016/9069054/

12. Asare EV, Olayemi E, Adomakoh Y, Mensah E, Swarray-Deen A, Ghansah H, et al. Low Body Mass Index in Pregnant Women with Sickle Cell Disease Is Associated with Premature Delivery in Sub- Saharan Africa. Blood. 2017 Dec 7;130(Suppl 1):2250-2250.

13. Oppong SA, Asare EV, Olayemi E, Boafor T, Dei-Adomakoh Y, Swarry-Deen A, et al. Multidisciplinary care results in similar maternal and perinatal mortality rates for women with and without SCD in a lowresource setting. Am J Hematol. 2019 Feb;94(2):223-30.

14. Report of the National High Blood Pressure Education Program Working Group on High Blood Pressure in Pregnancy. Am J Obstet Gynecol. 2000 Jul;183(1):S1-22.

15. Warhurst DC, Williams JE. ACP Broadsheet no 148. July 1996. Laboratory diagnosis of malaria. J Clin Pathol. 1996 Jul;49(7):533-8.

16. Miller MR, Hankinson J, Brusasco V, Burgos F, Casaburi R, Coates A, et al. Standardisation of spirometry. Eur Respir J. 2005 Aug 1;26(2):319-38.

17. Quanjer PH, Stanojevic S, Cole TJ, Baur X, Hall GL, Culver BH, et al. Multi-ethnic reference values for spirometry for the 3-95-yr age range: the global lung function 2012 equations. Eur Respir J. 2012 Dec;40(6):1324-43. 
18. O'Donnell DE, Aaron S, Bourbeau J, Hernandez P, Marciniuk DD, Balter M, et al. Canadian Thoracic Society recommendations for management of chronic obstructive pulmonary disease -2007 update. Can Respir J J Can Thorac Soc. 2007 Sep;14(Suppl B):5B.

19. Celli BR, Cote CG, Marin JM, Casanova C, Montes de Oca M, Mendez RA, et al. The body-mass index, airflow obstruction, dyspnea, and exercise capacity index in chronic obstructive pulmonary disease. N Engl J Med. 2004 Mar 4;350(10):1005-12.

20. Asare EV, Olayemi E, Boafor T, Dei-Adomakoh Y, Mensah E, Ghansah H, et al. Implementation of multidisciplinary care reduces maternal mortality in women with sickle cell disease living in low-resource setting. Am J Hematol. 2017 Sep;92(9):872-8.

21. Reynaud Q, Rousset Jablonski C, Poupon-Bourdy S, Denis A, Rabilloud M, Lemonnier L, et al. Pregnancy outcome in women with cystic fibrosis and poor pulmonary function. J Cyst Fibros Off J Eur Cyst Fibros Soc. 2019 Jul 1;

22. Lau EMT, Barnes DJ, Moriarty C, Ogle R, Dentice R, Civitico J, et al. Pregnancy outcomes in the current era of cystic fibrosis care: a 15-year experience. Aust N Z J Obstet Gynaecol. 2011 Jun;51(3):220-4.

23. Powars D, Weidman JA, Odom-Maryon T, Niland JC, Johnson C. Sickle cell chronic lung disease: prior morbidity and the risk of pulmonary failure. Medicine (Baltimore). 1988 Jan;67(1):66-76.

24. Boyd JH, Macklin EA, Strunk RC, DeBaun MR. Asthma is associated with increased mortality in individuals with sickle cell anemia. Haematologica. 2007 Aug;92(8):1115-8.

25. Dhakal B, Giese K, Santo-Thomas L, Field JJ. Death during an asthma exacerbation in an adult with sickle cell disease: an autopsy case study. Am J Hematol. 2013 Sep;88(9):824.

26. Kurl S, Jae SY, Kauhanen J, Ronkainen K, Laukkanen JA. Impaired pulmonary function is a risk predictor for sudden cardiac death in men. Ann Med. 2015 Jul 4;47(5):381-5.

27. Kassim AA, Payne AB, Rodeghier M, Macklin EA, Strunk RC, DeBaun MR. Low forced expiratory volume is associated with earlier death in sickle cell anemia. Blood. 2015 Sep 24;126(13):1544-50.

28. Magnussen C, Ojeda FM, Rzayeva N, Zeller T, Sinning CR, Pfeiffer N, et al. FEV1 and FVC predict all-cause mortality independent of cardiac function - Results from the population-based Gutenberg Health Study. Int J Cardiol. 2017 May 1;234:64-8.

29. Renton M, Priestley L, Bennett L, Mackillop L, Chapman S. Pregnancy outcomes in cystic fibrosis: a 10-year experience from a UK centre. Obstet Med. 2015 Jun;8(2):99-101.

30. Burden C, Ion R, Chung Y, Henry A, Downey DG, Trinder J. Current pregnancy outcomes in women with cystic fibrosis. Eur J Obstet Gynecol Reprod Biol. 2012 Oct;164(2):142-5.

TABLE 1 Characteristics of the study population of pregnant women with $\mathrm{FEV}_{1}$ [?]65\% compared to those with $\mathrm{FEV}_{1}<65 \%(\mathrm{n}=104)$

Outcomes

Maternal outcomes

Acute pain episode, events/patient year, mean (std. dev.)

ACS, events/patient

year, mean (std. dev.)

Preeclampsia, $n$ (\%),

$(n=103)$

Pregnant SCD women
with $\mathrm{FEV}_{1} \%$ predicted
$[?] 65 \% n=94$

$1.8(2.0)$

$0.4(1.0)$

$13(14.0)$
Pregnant SCD women

with $\mathrm{FEV}_{1} \%$ predicted

$<65 \% n=10$

$2.4(3.2)$

$1.0(1.7)$

$1(10.0)$ $p$-value*

$p-{ }^{2}$

0.827

0.201

1.000 


\begin{tabular}{|c|c|c|c|}
\hline $\begin{array}{l}\text { Hospitalization for } \\
\text { malaria, } n(\%),(n= \\
94)\end{array}$ & $22(25.3)$ & $4(57.1 \%)$ & 0.089 \\
\hline $\begin{array}{l}\text { Medically-assisted } \\
\text { delivery, } n(\%),(n \\
=101)\end{array}$ & $58(63.0)$ & $5(55.6)$ & 0.726 \\
\hline $\begin{array}{l}\text { Cesarean section } \\
\text { delivery, } n(\%),(n \\
=101)\end{array}$ & $58(63.0)$ & $4(44.4)$ & 0.302 \\
\hline $\begin{array}{l}\text { Maternal death }(\%) \\
\text { Neonatal outcomes }\end{array}$ & $2(2.1)$ & $1(10.0)$ & 0.264 \\
\hline IUGR, $n(\%),(n=101)$ & $7(7.6)$ & $0(0.0)$ & 1.000 \\
\hline $\begin{array}{l}\text { Preterm delivery, } n \\
(\%),(n=103)\end{array}$ & $26(28.0)$ & $5(50.0)$ & 0.163 \\
\hline $\begin{array}{l}\text { LBW }(<2500 \mathrm{~g}), n \\
(\%),(n=100)\end{array}$ & $25(27.2)$ & $2(25.0)$ & 1.000 \\
\hline $\begin{array}{l}\text { VLBW }(<1500 \mathrm{~g}), n \\
(\%),(n=100)\end{array}$ & $4(4.3)$ & $1(12.5)$ & 0.347 \\
\hline $\begin{array}{l}\text { Fetal death, } n(\%),(n \\
=103)\end{array}$ & $4(4.3)$ & $3(30.0)$ & 0.019 \\
\hline
\end{tabular}

Definition of abbreviations: BMI, body mass index; $\mathrm{FEV}_{1}$, forced expiratory volume in one second; FVC, forced vital capacity; SCD, sickle cell disease; IQR, interquartile range

${ }^{*} \mathrm{~T}$ test for mean difference or Fisher's exact test for percentage difference, unless otherwise indicated.

\#Mann-Whitney U test

TABLE 2 Maternal and neonatal outcomes of study participants with $\mathrm{FEV}_{1}[?] 65 \%$ compared to those with $\mathrm{FEV}_{1}<65 \%(n=104)$

\begin{tabular}{|c|c|c|c|}
\hline Outcomes & $\begin{array}{l}\text { Pregnant SCD women } \\
\text { with } \mathrm{FEV}_{1} \% \text { predicted } \\
{[?] 65 \% n=94}\end{array}$ & $\begin{array}{l}\text { Pregnant SCD women } \\
\text { with } \mathrm{FEV}_{1} \% \text { predicted } \\
<65 \% n=10\end{array}$ & $p$-value* \\
\hline \multicolumn{4}{|l|}{ Maternal outcomes } \\
\hline $\begin{array}{l}\text { Acute pain episode, } \\
\text { events/patient year, } \\
\text { mean (std. dev.) }\end{array}$ & $1.8(2.0)$ & $2.4(3.2)$ & 0.827 \\
\hline $\begin{array}{l}\text { ACS, events/patient } \\
\text { year, mean (std. dev.) }\end{array}$ & $0.4(1.0)$ & $1.0(1.7)$ & 0.201 \\
\hline $\begin{array}{l}\text { Preeclampsia, } n(\%) \\
(n=103)\end{array}$ & $13(14.0)$ & $1(10.0)$ & 1.000 \\
\hline $\begin{array}{l}\text { Hospitalization for } \\
\text { malaria, } n(\%),(n= \\
94)\end{array}$ & $22(25.3)$ & $4(57.1 \%)$ & 0.089 \\
\hline $\begin{array}{l}\text { Medically-assisted } \\
\text { delivery, } n(\%),(n \\
=101)\end{array}$ & $58(63.0)$ & $5(55.6)$ & 0.726 \\
\hline $\begin{array}{l}\text { Cesarean section } \\
\text { delivery, } n(\%),(n \\
=101)\end{array}$ & $58(63.0)$ & $4(44.4)$ & 0.302 \\
\hline Maternal death (\%) & $2(2.1)$ & $1(10.0)$ & 0.264 \\
\hline
\end{tabular}


Neonatal outcomes

IUGR, $n(\%),(n=101)$

Preterm delivery, $n$

$7(7.6)$

$26(28.0)$

$25(27.2)$

LBW $(<2500 \mathrm{~g}), n$

$(\%),(n=100)$

VLBW $(<1500 \mathrm{~g}), n$

$(\%),(n=100)$

Fetal death, $n(\%),(n$

$=103$ )
$0(0.0) \quad 1.000$

$5(50.0) \quad 0.163$

$2(25.0) \quad 1.000$

$4(4.3) \quad 1(12.5) \quad 0.347$

$4(4.3) \quad 3(30.0) \quad 0.019$

Definition of abbreviations: ACS, acute chest syndrome; IUGR, intrauterine growth restriction; LBW, low birth weight; SCD, sickle cell disease; VLBW, very low birth weight.

*Mann-Whitney U test for rates or Fisher's exact test for percentage difference.

TABLE 3 Multivariable penalized logistic regression models for fetal death among pregnant women with $\operatorname{SCD}(n=103)$.

\begin{tabular}{llll}
\hline & Odds ratio & $95 \%$ confidence interval & $p$-value \\
BMI & 1.00 & $0.84-1.20$ & 0.959 \\
Phenotype $(\mathrm{HbSS})$ & 3.41 & $0.68-17.19$ & 0.137 \\
FEV $_{1} \%$ predicted $<65 \%$ & 7.81 & $1.59-38.38$ & 0.011 \\
\hline
\end{tabular}

Definition of abbreviations: BMI, body mass index; $\mathrm{FEV}_{1}$, forced expiratory volume in one second

\section{Hosted file}

Figure 1--.jpg available at https://authorea.com/users/303688/articles/433858-1ow-fev1-isassociated-with-fetal-death-in-pregnant-women-with-sickle-cell-disease-a-prospectivecohort-study 